\title{
Excited delirium: Consideration of selected medical and psychiatric issues
}

\author{
Edith Samuel' \\ Robert B Williams' \\ Richard B Ferrell ${ }^{2}$ \\ 'Department of Psychology, Atlantic \\ Baptist University, Moncton, \\ New Brunswick Canada; ${ }^{2}$ Department \\ of Psychiatry, Dartmouth Medical \\ School, Lebanon, New Hampshire, USA
}

\begin{abstract}
Excited delirium, sometimes referred to as agitated or excited delirium, is the label assigned to the state of acute behavioral disinhibition manifested in a cluster of behaviors that may include bizarreness, aggressiveness, agitation, ranting, hyperactivity, paranoia, panic, violence, public disturbance, surprising physical strength, profuse sweating due to hyperthermia, respiratory arrest, and death. Excited delirium is reported to result from substance intoxication, psychiatric illness, alcohol withdrawal, head trauma, or a combination of these. This communication reviews the history of the origins of excited delirium, selected research related to its causes, symptoms, management, and the links noted between it and selected medical and psychiatric conditions. Excited delirium involves behavioral and physical symptoms that are also observed in medical and psychiatric conditions such as rhabdomyolysis, neuroleptic malignant syndrome, and catatonia. A useful contribution of this communication is that it links the state of excited delirium to conditions for which there are known and effective medical and psychiatric interventions.
\end{abstract}

Keywords: excited delirium, excited states, cocaine misuse, restraint or in custody deaths

\section{History}

The state referred to as agitated or excited delirium has its origins in the mid 1970s when cocaine intoxication was reported to result in cocaine psychoses. ${ }^{1}$ Aspects of these psychoses and more severe and lethal physical symptoms such as acute toxic psychosis, seizures, coma, respiratory collapse, and death were also observed in individuals attempting to smuggle packets of cocaine that leaked or broke in their bodies. ${ }^{2}$ Excited delirium was explicitly described in 1985 as a state resulting from cocaine intoxication involving acute intense paranoia, bizarreness, violence, surprising physical strength, hyperthermia, and fatal respiratory collapse within minutes or hours after restraint. ${ }^{3}$ An individual hospitalized in an excited and delirious state might meet the criteria for substance intoxication delirium and mania. Substance intoxication delirium involves disorientation, disruption of awareness, inability to attend, confusion, perceptual difficulties, and inappropriate responses to changing situations. The excitement can be seen as similar to the excitement of the acute phase of bipolar mania with grandiosity, distractibility and psychomotor agitation. ${ }^{4}$

Excited delirium has been acknowledged as being among several acute excited states such as catatonic excitement or delirious mania. ${ }^{5}$

In this regard, the behavioral excitement aspect of excited delirium is quite similar to the excitement seen in catatonic excitement. Patients' behavior in catatonic excitement may be "stereotypic with sudden outbursts of talking, singing, dancing, and tearing at their clothes. They become irritable and may damage objects or injure hospital staff". ${ }^{6}$ Taylor ${ }^{6}$ observes that catatonic excitement is difficult to differentiate from delirious mania. According to Fink, ${ }^{7}$ delirious mania is seen in the emergence of severe "excitement, grandiosity, emotional lability, delusions, and insomnia 
characteristic of mania, and the disorientation and altered consciousness characteristic of delirium. Almost all patients exhibited signs of catatonia." Catatonia signs may involve physical immobility seen as cataleptic or stuporousness, excessive purposeless physical activity, serious negativism or mutism, idiosyncratic voluntary movements, echolalia involving the repetition of words or phrases, or ecopraxia involving repetitive copying of another person's movements. ${ }^{4}$ The most likely catatonia signs manifested by persons in a state of excited delirium would be excitement manifested in excessive purposeless physical activity, idiosyncratic voluntary movements, echolalia and/or echopraxia.

\section{Issues regarding excited delirium}

Excited delirium has gained public notice because it has so often been among the post-mortem explanations offered by medical examiners in the deaths of individuals during the process of being restrained by law enforcement to be taken into custody or while being held in custody. ${ }^{8-16}$ Studies by medical examiners have focused on determining the causes of the deaths of individuals described as being in a state of excited delirium prior to and after being restrained and whether or how restraint may have played a role in the deaths of these individuals. ${ }^{17-19}$ The prevalence of agitated or excited delirium is uncertain and studies have tended to focus on deceased victims. ${ }^{11}$ An informative result of the studies is the finding that excited delirium is not only due to substance intoxication but also to psychiatric illness, alcohol withdrawal, head trauma or a combination of these conditions. ${ }^{8-11,14}$ The case presented below is an example of the context within which many persons in a state of excited delirium are encountered by law enforcement and emergency services.

\section{A case of untreated excited delirium and sudden death}

This case was abstracted from selected news articles by Babstock $^{20-24}$ on a coroner's inquest into the death of a man while police were restraining him in order for him to be rehospitalized. The 34-year-old man had a history of major psychiatric illness which was diagnosed as bipolar disorder when he was 18 years old. It is reported that treatment was occasionally affected by his use of marijuana, hashish, LSD, and amphetamines. During the several years before his death, this patient was seen every few weeks by a psychiatrist who described him as doing well or, at times, as hypomanic or depressed. He was an unpredictable patient who could not be depended upon to take his prescribed medication or avoid using marijuana. Hospitalization was required for a psychotic episode during which he had delusions of persecution and was ranting about religious topics. He was restricted to a locked unit for patients considered dangerous to self and others for two days. By the third day of hospitalization, he was transferred to an open unit on the basis of his improved demeanor and compliance with treatment. He was not permitted to leave the open unit-not even for a cigarette. Later on the same day that he had been transferred, at about 9:00 PM, he walked off the unit telling a psychiatric attendant pursuing him that he was going for a cigarette. At 9:30 PM, it was determined that he had left the hospital and the police were notified. He had apparently gotten a cab and requested to be taken to several places. The driver stopped the cab after the man grabbed the steering wheel. The patient left the cab and made his way to a lounge. At the lounge, he was reported to be talking to mirrors, asking questions and walking back and forth in front of the bar. His behavior caused the proprietor to call for police assistance. When the police arrived to return him to the hospital, he refused and attempted to avoid being restrained. He was described as sweating, breathing heavily, and with dilated pupils. His attempt to avoid restraint resulted in smashed tables and injury of a police officer. The police used pepper spray and Taser in attempting to restrain him. It took four officers to subdue him and almost immediately after being restrained he stopped breathing. Cardiopulmonary resuscitation was initiated and a call was made for emergency medical assistance. Attempts to resuscitate him were unsuccessful. During the coroner's inquest it was noted that he was obese, had asthma, an enlarged heart, and had eight Taser wounds. Ultimately, an expert's testimony attributed his death to excited delirium. His history of substance misuse and psychiatric illness are two possible antecedents to his state of excited delirium. It is noteworthy that this case is similar in its outcome to many others in that the client died while being restrained to be taken into custody (eg, Bast $\left.{ }^{15}\right)$.

\section{A diagnostic problem}

Concern has been expressed that although the state of excited delirium is given as an explanation for in-custody deaths, it is currently not a recognized medical or psychiatric diagnosis according to either the Diagnostic and Statistical Manual of Mental Disorders (DSM-IVTR) of the American Psychiatric Association $^{4}$ or the International Classification of Diseases (ICD-9) of the World Health Organization. ${ }^{25-27}$ Yet it is important to note that a lack of recognition does not negate the seriousness of the behavioral and physical symptoms referred to as excited delirium. It is noteworthy that one 
study found that only 18 of 214 individuals identified as manifesting excited delirium died when restrained and taken into custody. ${ }^{12}$ Unfortunately, the study did not report if or whether the survivors were diagnosed or treated.

\section{Rhabdomyolysis, neuroleptic malignant syndrome, and catatonia}

Cocaine-intoxicated individuals in a state of excited delirium have been reported to have cocaine blood level concentrations ten times lower than individuals who died of cocaine overdoses without excited delirium. The excited delirium and lower cocaine levels is explained as due to modifications of dopamine processing resulting from habitual cocaine use. ${ }^{18}$ Studies have noted that survivors of cocaine intoxication with excited delirium have also been reported to develop rhabdomyolysis which results in skeletal muscle breakdown and leakage of muscle substance into the circulatory system that has clinical similarities to neuroleptic malignant syndrome (NMS). ${ }^{17,18,28-30}$ Ruttenber and colleagues ${ }^{17}$ maintain that excited delirium and cocaine-induced rhabdomyolysis are aspects of the same syndrome that is likely due to chronic cocaine use. The issue of the clinical similarities between cocaine induced rhabdomyolysis and NMS points to the speculation of whether cocaine rhabdomyolysis is a form of NMS. ${ }^{29,31}$ Neuroleptic malignant syndrome is manifested in severe muscle rigidity, fever, cognitive confusion, elevated creatinine phosphokinase and/or white blood count levels allegedly related to the administration of neuroleptic medications., ${ }^{4,32}$ A 1991 study found that cocaine abusers treated with neuroleptics developed NMS whereas nonabusers did not. ${ }^{33}$ Khaldarov $^{34}$ successfully treated a patient, with a history of cocaine abuse and recent treatment with fluphenazine, with lorazepam on the basis of the assumption that cocaine-associated rhabdomyolysis with hyperthermia and NMS are the same condition.

Lopez-Canino and Francis, ${ }^{35}$ in their review of the literature on drug-induced catatonia from the study of phencyclidine intoxication by McCarron and colleagues, ${ }^{36}$ also noted an association between rhabdomyolysis and catatonia. Other studies have reported an association between psychosis (eg, mania and schizophrenia) involving overactivity, catatonia and rhabdomyolysis. ${ }^{37-39}$ In sum, the literature appears to suggest some association between the state of excited delirium, rhabdomyolysis, NMS and even catatonia. Studies have also noted that NMS and catatonia seem to be different aspects of the same syndrome (cf, Fink; ${ }^{40}$ Carroll; ${ }^{41}$ Koch and colleagues $^{42}$ ). Petrides and colleagues ${ }^{43}$ propose that NMS itself is a form of catatonia whose features are similar to those of malignant catatonia and that they may both benefit from similar treatment.

The association researchers have established between excited delirium and the potentially life-threatening syndromes of rhabdomyolysis, NMS, and catatonia give impetus to the need for critical emergency medical interventions when encountering a person thought to be in a state of excited delirium.

\section{A case of treated excited delirium}

Petrides and colleagues ${ }^{43}$ report on treating a patient " ... in a state of excited delirium following intrethecal administration of an analgesic for chronic pain" (for the original report see Levin and colleagues ${ }^{45}$ ). Symptoms included purposeless agitation, stiffness, serious negativism or mutism, and staring. Creatine phosphokinase level remained elevated. His temperature was quite high and he required physical restraint. There was no benefit from intravenous haloperidol, lorazepam, or midazolam. The delirium remained refractory and the patient required intensive care with intubation and ventilation. By the 18th day of hospitalization it was determined that electroconvulsive therapy (ECT) should be initiated and five treatments were administered during thee days. On the 21st day of hospitalization, after a final ECT, he was able to interact with his wife. He improved and had no memory of his illness and was able to return to part-time work. After three months he was regarded as fully recovered (cf, Levin and colleagues ${ }^{45}$ ). Petrides and colleagues ${ }^{43}$ retrospectively reported this patient as an example of someone manifesting "atypical catatonic features". Interestingly, in the original case report there was no discussion of catatonia and the administration of ECT appears to have been initiated to treat the delirium (cf, Strömgren; ${ }^{45}$ Fink $^{46}$ ). This is noteworthy in view of the fact that the DSM-IVTR guidelines for catatonia due to a medical condition would not apply to an individual manifesting a delirium to ensure that the medical source of the delirium is resolved. ${ }^{4}$ The success of the intervention in this instance suggests that even a delirium due to a medical condition refractory to other interventions may benefit from those specifically designated for catatonia such as high doses of lorazepam (12 to $20 \mathrm{mg} /$ day) or ECT when the lorazepam is not effective.

There are some similarities between the state of excited delirium and catatonia that may be best seen in examining case examples of catatonia when the catatonia involves agitation and excessive physical or motor activity. Below are two case examples of catatonia in individuals with symptoms of agitation and excessive physical activity (cases from Ferrell and Williams ${ }^{47}$ ). 


\section{Case examples of catatonia Case A}

This is the case of a 75-year-old woman with a history of major psychiatric illness, which was diagnosed as schizophrenia when she was in her 20s. She subsequently suffered a hemorrhagic stroke from an anterior communicating artery aneurysm in her 20s. Both frontal lobes sustained extensive destruction and a more severe mental syndrome emerged after the stroke. Many years of psychiatric hospitalization resulted. The treatments initiated included 80 ECT treatments, many hours of continuous baths, insulin coma therapy, various anti-psychotic medicines and assorted psychotropic drugs, including anticonvulsants. She had severe tardive dyskinesia. At age 75 an episode of extreme agitation with catatonic symptoms of constant motor activity, disrobing, marked negativism, echolalia and echopraxia occurred. Her creatine kinase value was $>2400$. Treatment was initiated by discontinuing her previously prescribed haloperidol and initiation of lorazepam up to 16 milligrams per day in divided doses. The catatonic syndrome remitted and did not recur. Treatment with low dose lorazepam was continued. Antipsychotic medications were not restarted and there was no return of psychotic symptoms.

\section{Case B}

A 74-year-old woman first experienced the onset of delusional symptoms at age 21 . At that time, she was assessed and attained a full scale IQ of 70 . Her symptoms were diagnosed as indications of schizophrenia. She recovered from this initial illness and lived a quiet productive life in the care of her family until age 51. After a "flu-like illness," she attempted to return to her assembly-line job where she was found standing mute and motionless on the line. She required hospitalization and received institutional care until her death almost 30 years later. While suffering a severe neuropsychiatric illness she manifested sustained periods of social withdrawal, posturing, and muteness. At age 74 she suffered an episode of severe excitement, agitation, delirium, sleeplessness and dehydration. The syndrome was life threatening. Results of a magnetic resonance imaging (MRI) study revealed advanced cerebral atrophy without focal findings as had several prior computed tomography (CT) scans. An electroencephalograph (EEG) was normal. There was a history of prior protracted periods of severe agitation and yelling as observed at age 74, though less severe. Prior treatment with medication was marginally successful, including trials of typical antipsychotic drugs, antidepressants, lithium, diphenhydramine, chloral hydrate, divalproex sodium, methylphenidate, and benzodiazepines. She responded well to six ECT treatments. After a relapse, she recovered with 12 additional ECT treatments. The catatonia did not recur with clozapine prophylaxis during the remaining six years of her life. ECT treatment was regarded as life-saving for this patient.

In both the untreated and treated cases of excited delirium the symptoms were unexpected as were the symptoms of catatonia in the cases discussed above. The serious difference in the outcomes was the fact that the individuals - one in a state of excited delirium and two with catatonia - who were hospitalized were expeditiously diagnosed and treated. Regarding medical care and excited delirium, Stratton and colleagues ${ }^{12}$ have made the observation "... that unexpected sudden death when excited delirium victims are restrained in the out-of-hospital setting is not infrequent and can be associated with multiple predictable but usually uncontrollable factors."

\section{Discussion}

It is noteworthy that excited delirium, NMS and catatonia may result in many physical symptoms that are similar such as profuse sweating, dehydration, electrolyte imbalance, fever, tachycardia, hypertension, rapid breathing, and the

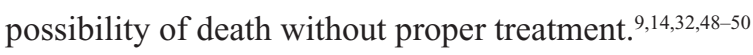

Treatment recommended for excited delirium, NMS and catatonia are quite similar. Selected aspects of the treatment approach for excited delirium reported here are based upon recommendations in Karch and Stephens, ${ }^{10}$ Petrides and colleagues $^{43}$ (cf Levin and colleagues ${ }^{45}$ ), and Sztajnkrycer and Baez. ${ }^{14}$ Individuals manifesting excited delirium should be evaluated for their medical needs on an emergency basis. They should especially receive temperature, oximetry and cardiac monitoring. Temperature management interventions should be initiated as necessary. Due to the psychomotor agitation during the state of excited delirium, treatment with benzodiazepines, and possibly in high doses is recommended. Neuroleptics are not recommended due to the possible adverse influence on temperature regulation, seizure threshold and arrhythmia. If benzodiazepines are not effective, ECT should be considered as it was in the excited delirium case reported by Petrides and colleagues. ${ }^{43}$

In sum, the association between the state of excited delirium and the potentially life-threatening syndromes of rhabdomyolysis, NMS and catatonia give impetus to the need for critical emergency medical care for persons encountered in a probable state of excited delirium. Rigorous effort should be aimed at establishing the best possible understanding of 
relevant medical and psychiatric diagnosis. Correct diagnosis leads to rational and effective treatment. Research into understanding and managing excited delirium may receive considerable benefit from examining the documentation on the diagnosis and care of persons with rhabdomyolysis, NMS and catatonia for which there are known and effective medical and psychiatric interventions.

\section{Disclosure}

The authors report no conflicts of interest in this work.

\section{References}

1. Post RM. Cocaine psychoses: A continuum model. Am J Psychiatry. 1975;132:225-231.

2. Wetli CV, Mittleman RE. The "body packer syndrome"-toxicity following ingestion of illicit drugs packaged for transportation. J Forensic Sci. 1981;26:492-500.

3. Wetli CV, Fishbain DA. Cocaine-induced psychosis and sudden death in recreational cocaine users. J Forensic Sci. 1985;30:873-880.

4. American Psychiatric Association. Diagnostic and statistical manual of mental disorders. 4th ed. Washington, DC: American Psychiatric Association Press; 2000.

5. Farnham FR, Kennedy HG. Acute excited states and sudden death: Much journalism, little evidence. Brit Med J. 1997;315:1107-1108.

6. Taylor MA. Clinical examination. In: Caroff SN, Mann SC, Francis A, Fricchione GL, editors. Catatonia: From Psychopathology to Neurobiology. Arlington, VA: American Psychiatric Publishing Inc; 2004. p. 45-52.

7. Fink M. Delirious mania. Bipolar Disord. 1999;1:54-60.

8. O'Halloran RL, Lewman LV. Restraint asphyxiation in excited delirium. Am J Forensic Med Pathol. 1993;14:289-295.

9. Pollanen MS, Chiasson DA, Cairns JT, Young JG. Unexpected death related to restraint for excited delirium: A retrospective study of deaths in police custody and in the community. Can Med Assoc J. 1998; 1587:1603-1607.

10. Karch SB, Stephens BG. Drug abusers who die during arrest or in custody. J Royal Soc Med. 1999;92:110-113.

11. Park KS, Korn CS, Henderson SO. Agitated delirium and sudden death: Two case reports. Prehosp Emer Care. 2001;5:214-216.

12. Stratton SJ, Rogers C, Brickett K, Gruzinski G. Factors associated with sudden death of individuals requiring restraint for excited delirium. $\mathrm{Am}$ J Emerg Med. 2001;19:187-191.

13. Laur D. Excited delirium and its correlation to sudden and unexpected death proximal to restraint: A review of the current and relevant medical literature. Canadian Police Research Centre [online]. 2004. [Cited Jul 18, 2007.] Available from: http://www.cprc.org/tr/tr-2005-02_e.pdf.

14. Sztajnkrycer MD, Baez AA. Cocaine, excited delirium and sudden unexpected death [online]. 2005. [Cited Mar 2, 2007.] Available from: $\mathrm{http}: / /$ www.emsresponder.com.

15. Bast MR. Report to the Minister of Justice and Attorney General: Public fatality inquiry [online]. 2007. [Cited Feb 25 2008.] Available from: http://www.justice.gov.ab.ca/downloads/documentloader. aspx?id=48177.

16. Sathyavagiswaran L, Rogers C, Noguchi TT. Restraint asphyxia in in-custody deaths: Medical examiners role in prevention. Legal Med. 2007;9:88-93.

17. Ruttenber AJ, Lawler-Heavner J, Yin M, Wetli CV, Hearn WL, Mash DC. Fatal excited delirium following cocaine use: Epidemiologic findings provide new evidence for mechanisms of cocaine toxicity. J Forensic Sci. 1997;42:25-31.

18. Ruttenber AJ, McAnally HB, Wetli CV. Cocaine-associated rhabdomyolysis and excited delirium: Different stages of the same syndrome. Am J Forensic Med Pathol. 1999;20:120-127.
19. Ross DL. Factors associated with excited delirium deaths in police custody. Mod Pathol. 1998;11:1127-1137.

20. Babstock C. Taser death inquest begins. Feb 22, 2007. Times and Transcript. [Moncton NB Canada]. p. A1, A6.

21. Babstock C. Taser death inquest told: Smoke break provided escape chance. Feb 23, 2007. Times and Transcript. [Moncton NB Canada]. p. A1-A9.

22. Babstock C. Police describe violent confrontation with Taser victim. Feb 27, 2007. Times and Transcript. [Moncton NB Canada]. p. A1-A7.

23. Babstock C. Corner's inquest told: Man's death likely even without Taser shock. Mar 1, 2007. Times and Transcript. [Moncton NB Canada]. p. A1-A2.

24. Babstock C. Coroner's inquest concludes: Taser death of Metro man ruled accidental. Mar 3, 2007. Times and Transcript. [Moncton NB Canada]. p. A1-A10.

25. Paquette M. Excited delirium: Does it exist? Perspect Psychiatr Care. 2003;39:93-94.

26. Lawrence C. PoliceOne Exclusive: Excited delirium and its medical status [online]. 2006. [Cited Aug 16, 2007.] Available from: http:// policeone.com/writers/columnists/ChrisLawrence/articles/121675.

27. Lawrence C. Excited delirium and its medical status, Part 2: If excited delirium isn't in the DSM, what is? Canadian Police Research Centre [online]. 2006. [Cited Aug 16, 2007.] Available from: http://policeone. com/writers/columnists/ChrisLawrence/articles/126389.

28. Roth D, Alarcon FJ, Fernandez JA, Preston RA, Bourgoignie JJ. Acute rhabdomyolysis associated with cocaine intoxication. $N$ Engl $J$ Med. 1988;319:673-677.

29. Daras M, Kakkouras L, Tuchman AJ, Koppel BS. Rhabdomyolysis and hyperthermia after cocaine abuse: A variant of the neuroleptic malignant syndrome? Acta Neurol Scand. 1995;92:161-165.

30. Sauret JM, Marinides G, Wang GK. Rhabdomyolysis. Am Fam Physician. 2002;65:907-912.

31. Wetli CV, Mash D, Karch SB. Cocaine-associated agitated delirium and neuroleptic malignant syndrome. Am J Emerg Med. 1996;14:425-428.

32. Pelonero AL, Levenson JL, Pandurangi AK. Neuroleptic malignant syndrome: A review. Psychiatr Serv. 1998;49:1163-1172.

33. Akpaffiong MJ, Ruiz P. Neuroleptic malignant syndrome: A complication of neuroleptics and cocaine abuse. Psychiatr Q. 1991;62: 299-309.

34. Khaldarov V. Benzodiazepines for treatment of neuroleptic malignant syndrome. Hosp Phys. 2000;36:51-55.

35. Lopez-Canino A, Francis A. Drug-induced catatonia. In: Caroff SN, Mann SC, Francis A, Fricchione GL, editors. Catatonia: From Psychopathology to Neurobiology. Arlington, VA: American Psychiatric Publishing Inc; 2004. p. 129-139.

36. McCarron MM, Schulze BW, Thompson GA, Conder MC, Goetz WA. Acute phencyclidine intoxication: Clinical patterns, complications, and treatment. Ann Emerg Med. 1981;10:290-297.

37. Coryell W, Norby L, Cohen L. Psychosis induced by rhabdomyolysis. Lancet. 1978;8085:381-382.

38. Frankel AS, Prassad RB. Rhabdomyolysis, renal failure and schizophrenia. Psychiatr J Univ Ott. 1989;141:296-297.

39. Manchip SM, Hurel SJ. Rhabdomyolysis due to mania. Br J Psychiatry. 1995;167:118-119.

40. Fink M. Recognising NMS as a type of catatonia. Neuropsychiatry Neuropsychol Behav Neurol. 1995;8:75-76.

41. Carrol BT. The universal field hypothesis of catatonia and neuroleptic malignant syndrome. CNS Spectr. 2000;5:26-33.

42. Koch M, Chandragiri S, Rizvi S, Petrides G, Francis A. Catatonic signs in neuroleptic malignant syndrome. Compr Psychiatry. 2000;41:73-75.

43. Petrides G, Malur C, Fink M. Convulsive therapy. In: Caroff SN, Mann SC, Francis A, Fricchione GL. editors. Catatonia: From Psychopathology to Neurobiology. Arlington, VA: American Psychiatric Publishing Inc; 2004. p. 151-160.

44. Strömgren LS. ECT in acute delirium and related clinical states. Convuls Ther. 1997;13:10-17. 
45. Levin T, Petrides G, Weiner J, Saravay S, Multz AS, Bailine S. Intractable delirium associated with ziconotide successfully treated with electroconvulsive therapy. Psycosomatics. 2002;43:63-66.

46. Fink M. ECT in delirious states [editorial]. J ECT. 1999; 15:175-177.

47. Ferrell RB, Williams RB. Recognizing catatonia in older patients: A five case study [abstract]. Rome, Italy: Prog Bk Intern Psychogeriatric Ass European and Mediterranean Reg Mtg; April 17-20, 2002; p. 47-48.

48. Benner AW, Issacs SM. "Excited delirium": A two-fold problem [online]. Police Chief. 1996. [Cited Mar 2, 2007.] Available from: http://www. zarc.com/english/other_sprays/reports/excited_delirium.html.
49. Mann SC, Caroff SN, Fricchione GL, Campbell EC, Greenstein RA. Malignant catatonia. In: Caroff SN, Mann SC, Francis A, Fricchione GL, editors. Catatonia: From Psychopathology to Neurobiology. Arlington, VA: American Psychiatric Publishing Inc: 2004. p. 105-119.

50. Gross AF, Smith FA, Stern TA. Dread complications of catatonia: A case discussion and review of literature. Prim Care Companion J Clin Psychiatry. 2008;10:153-155. 